\title{
Влияние сортовых особенностей винограда на качество и состав летучих веществ молодых коньячных дистиллятов
}

\author{
Ольга Алексеевна Чурсина, д-р техн. наук, ст. науч. сотр., гл. науч. сотр. лаборатории коньяка, olal45@mail.ru, \\ тел. (3654) 23-40-95, https://orcid.org/0000-0003-4976-0871; \\ Людмила Алексеевна Легашева, мЛ. науч. сотр. лаборатории коньяка, lusi2402@gmail.com; \\ Виктор Афанасьевич Загоруйко, д-р техн. наук, профессор, гл. науч. сотр. лаборатории коньяка, зав. лабораторией \\ коньяка, vikzag51@gmail.com; \\ Людмила Михайловна Соловьева, канд. техн. наук, ст. науч. сотр., вед. науч. сотр. лаборатории коньяка, \\ luda_magarach@mail.ru; \\ Александр Ефимович Соловьев, науч. сотр. лаборатории коньяка, weinbauer@mail.ru; \\ Елена Леонидовна Удод, науч. сотр. лаборатории коньяка, upupa.epops@yandex.ru; \\ Алина Васильевна Мартыновская, мл. науч. сотр. лаборатории экспериментального виноделия и коллекционных \\ вин, alino4ka81292@mail.ru; \\ Станислав Олегович Ульянцев, мл. науч. сотр. лаборатории тихих вин, stas06121@mail.ru; \\ Зоя Ивановна Гаске, вед. инженер лаборатории коньяка \\ Федеральное государственное бюджетное учреждение науки «Всероссийский национальный научно-исследовательский институт \\ виноградарства и виноделия «Магарач» РАН», Россия, Республика Крым, 298600, г. Ялта, ул. Кирова, 31
}

\begin{abstract}
В статье пре дставлены результаты исследования состава летучих веществ виноматериалов для про изводства коньяков и молодых коньячных ди стиллятов, выработанных из интродуцированных сортов винограда, сортов селекции Института «Магарач» и аборигенного сорта Крыма. Выявлены основные критерии оценки качества винограда для коньячного производства и установлена их тесная связь с содержанием летучих примесей в коньячных виноматериалах и молодых дистиллятах. Установлено, что наиболее значимыми из исследуемых показателей качества винограда являются массовая концентрация сахаров, титруемых кислот, фенольных соединений сусла, технологический запас фенольных веществ в винограде, величина рН сусла и монофенолмонооксиг еназная активность. Выведены уравнения регрессии, устанавливающие зависимость содержания летучих примесей виноматериалов и молодых коньячных дистиллятов от показателей качества винограда. Проведена оценка влиян ия сорта винограда на качество коньячных ви номатериалов и дистиллятов. Показано, что образцы, полученные из интродуцированных сортов винограда, характеризуется высокими зна чениями соотношения средних эфиров и высших спиртов, что свидетельствует о высоком их качестве. Особенностью состава коньячных виноматериалов и дистиллятов из селекционных сортов является высокая доля высших спиртов и сравнительно низкая - средних эфиров. Повышению критерия способствует переработка винограда при сахаристости не ниже 160 г/дм ${ }^{3}$.
\end{abstract}

Ключевые слова: сорт винограда; виноматериал; молодой коньячный дистиллят; высшие спирты; средние эфиры; качество.

\section{Как цитировать эту статью:}

Чурсина О.А., Легашева Л.А., Загоруйко В.А., Соловьева Л.М. Соловьев А. Е Удод Е Л. Мартыновская А. Ульянцев С.О., Гаске З.И. Влияние сортовых особенностей винограда на качество и состав летучих веществ молодых коньячных дистиллятов // «Магарач». Виноградарство и виноделие, 2019; 21 (2). С.168-173. DOI 10.35547/IM.2019.21.2.018

How to cite this article:

Chursina O.A., Legasheva L.A., Zagorouiko V.A., Solovyova L.M., Solovyov A.E., Udod E.L., Martynovskaya A.V. Uluantsev S.O., Gaske Z.I. The effect of grapvine varietal features on the quality and composition of volatile substances of young brandy distillates // Magarach. Viticulture and Winemaking, 2019; 21(2). - pp. 168-173. DOI 10.35547/IM.2019.21.2.018

УДК 663.241:663.253.1/.32:66.048

Поступила 15.05.2019

Принята к публикации 16.05.2019

(С)Авторы, 2019
0 R I G I N A L A R T I C L E

\section{The effect of grapvine varietal features on the quality and composition of volatile substances of young brandy distillates}

Olga Alekseevna Chursina, Ludmila Alekseevna Legasheva, Victor Afanasievich Zagorouiko, Lyudmila Mikhailovna Solovyova, Alexander Efimovich Solovyov, Elena Leonidovna Udod, Alina Vasilyevna Martynovskaya, Stanislav Olegovich Uluantsev, Zoya Ivanovna Gaske

Federal State Budget Scientific Institution All-Russian National Research Institute of Viticulture and Winemaking Magarach of RAS, 31 Kirova Street, 298600 Yalta Republic of Crimea, Russia

The article presents study findings on the volatile composition of wine materials for the production of brandies and young brandy distillates produced from introduced g rapevine cultivars, cultivars of the Institute Magarach breeding and native Crimean varieties. The main quality assessment criteria to determine suitability of grapes for brandy production have been identified. Their close relationship was established with the volatile impurities content in brandy wine materials and young distillates. Mass concentration of sugars, titrated acids, must phenolic compounds, technological reserve of phenolic compounds in grapes, must $\mathrm{pH}$, and monophenolmonooxygenase activity were determined to be the most significant of the studied quality parameters of grapes. The regression equations were derived to determine the correlation between the volatile impurities content of the base wines and young brandy distillates and grape quality indicators. The effect of grapevine cultivar on the quality of wine and brandy distillates was assessed. It was demonstrated that samples obtained from introduced grapevine cultivars were characterized by high values of the medium esters and higher alcohols ratio indicating their high quality. A high proportion of higher alcohols and a relatively low proportion of medium esters is a notable feature of the composition of brandy base wines and distillates made of selection cultivars. Processing of grapes when sugar content is at least $160 \mathrm{~g} / \mathrm{dm}^{3}$ helps to improve the criterion.

Key words: grapevine cultivar; base wine; young brandy distillate; higher alcohols; medium esters; quality.

$\mathrm{B}$ ведение. Качество молодых коньячных дистимлятов в значительной мере определяется метучими примесями, перехоАящими в спирт при перегонке виноматериала. Уровень их накопцения в виноматериале зависит от многих факторов: сорта винограАа, агротехники его выращивания, состава почвы, кмиматических условий, способа переработки, применяемых рас Арожжей, условий брожения и Ар. [1-15].

Расширение сырьевой базы виноделия в районы укрывного виноградарства обусловило перспективность использования селекционных сортов винограда, характеризующихся высокой урожайностью и устойчивостью к различным неблагоприятным биотическим и абиотическим факторам [9, 16-18].

Исследования устойчивости сортов винограда к низким тем- 
пературам, проведенные рядом авторов, свидетемьствуют о разАичных биохимических механизмах иммунитета растения, определяющих особенности белкового ими углеводного обменов, синтеза разцичных компонентов, выполняющих защитную роль (белков, высокомолекулярных углевоАов, фенольных соеАинений, минерамьных веществ, сахарозы и Ар.), изменение характера окислительно-восстановительных процессов в клетке, интенсивности окис$\Lambda$ ительных ферментов и т.А. [19-23]. Биологические характеристики сорта винограда, их специфичность оказывают решающее влияние на физико-химический состав и качество винодецьческой продукции, оАнако воздействие на биохимические показатели винограда Аля коньячного производства и качество моцодых коньячных Аистиццятов изучено недостаточно.

Целью настоящей работь явцямось изучение влияния биохимических показатемей винограда на состав ароматобразующих веществ молодых коньячных Аистиццятов.

\section{Материалы и методы исследований}

Материалами исследований являмись винограА урожая 2015-2018 гг. интродуцированных сортов (Амиготе, Совиньон земеный, Ркацитеми, Комомбар, Уни Бман), сортов селекции Института «Магарач» (Первенец Магарача, Рислинг Магарача, Перцинка, Аврора Магарача), аборигенного сорта (Шабаш), произрастающих в Авух географических зонах Республики Крым: ПреАгорной (пгт. Вимино Бахчисарайского p-на) и Южнобережной восточного и западного районов (пгт. Коктебель, г. ФеоАосия, г. ЯАта); коньячные виноматериалы, полученные в условиях микровиноделия по стандартной технологии (Аробление винограда с гребнеотделением, отАеление сусла, отстаивание сусла 12 ч при температуре $10-12^{\circ} \mathrm{C}$, брожение сусла с использованием чистых кумьтур Арожжей из комлекции микроорганизмов виноделия ФГБУН «ВННИИВиВ «Магарач» РАН») [24]. Аистимцяцию виноматериалов осуществця$\Lambda$ и на стендовой установке методом Авойной сгонки по шарантской технологии. Всего было использовано 50 партий винограда, выработано 150 партий виноматериацов и моцодыХ коньячныХ Аистиццятов.

Анализ винограда осуществ яли согласно «Методике оценки сортов винограда по физико-химическим и биохимическим показатемям» (РА 0033483.042-2005) [25], вкцючающей, кроме основных показателей углеводно-кислотного состава, также показатели техноцогического запаса фенольных веществ в винограде (ТЗФВ), массовой концентрации феномьных компонентов сусла после прессования цемых ягоА $\left(Ф B_{\text {исх }}\right)$ и после настаивания мезги $\left(\Phi B_{\text {нм }}\right)$, мацерирующую способность винограда $\left(\Phi B_{\text {мац. }}\right)$, способности винограда к окислению $\left(\Phi \mathrm{B}_{\text {ок }}\right)$ и к отАаче фенольных веществ $\left(Ф \mathrm{~B}_{\text {от }}\right)$, а также монофеноммонооксигеназную (МФМО) и уАельную ферментативную активности сусла сразу после Аробления винограда.

Анациз химического состава виноматериалов и молодых коньячных Аистиццятов проводици общепринятыми методами [26], а также с использованием газового хроматографа Agilent Technology 6890 с масс-спектрометрическим детектором (колонка кварцевая капимлярная НP-innowax, газ-носитель - гелий).

В работе использоваци микробиологически стойкие виноматериацы, по качеству не ниже уАовлетворитемьной оценки. Органолептическую оценку виноматериалов и Аистиццятов проводили с привцечением Аегустационной комиссии ФГБУН «ВННИИВиВ «Магарач» РАН».

Результаты провеАенных исслеАований систематизировали, обрабатываци методами математической статистики, испомьзуя корреляционный и регрессионный анализы с применением программного обеспечения компьютерных техномогий.

\section{Результаты и их обсуждение}

Анализ углеводно-кислотно-фенольного состава и биохимических показателей сортов винограАа, провеАенный с учетом их принаАлежности к оАной из условных групп (интродуцированные, селекционные и аборигенные сорта), показаца некоторые разцичия межАу ними по ряду признаков (табц.).

Таблица. Оценка физико-химических и биохимических показателей сортов винограда урожая 2015-2018 гг.

Table. Assessment of physical-chemical and biochemical indicators of grapes of the 2015-2018 harvest

\begin{tabular}{|c|c|c|c|}
\hline \multirow{2}{*}{ Наименование показатемя } & \multicolumn{3}{|c|}{$\begin{array}{l}\text { Сорта винограда (группа) } \\
\text { диапазон/среднее значение }\end{array}$} \\
\hline & $\begin{array}{l}\text { интродуци- } \\
\text { рованные }\end{array}$ & $\begin{array}{l}\text { селекцион- } \\
\text { ные }\end{array}$ & $\begin{array}{l}\text { абориген- } \\
\text { ные }\end{array}$ \\
\hline $\begin{array}{l}\text { Массовая концентрация сахаров сус } а \text {, } \\
\text { г/АM }{ }^{3}(\mathrm{Cax})\end{array}$ & $\frac{122,0-238,0}{187,8}$ & $\frac{124,0-252,0}{173,9}$ & $\frac{132,0-18}{156,6}$ \\
\hline $\begin{array}{l}\text { Массовая концентрация титруемых } \\
\text { кислот, г/Ам }{ }^{3}(\mathrm{TK})\end{array}$ & $\frac{5,0-10,8}{7,9}$ & $\frac{5,5-12,2}{8,1}$ & $\frac{2,9-6,6}{4,7}$ \\
\hline Вемичина рН сусла (рН), еА. & $\frac{2,9-3,4}{3,1}$ & $\frac{2,8-3,6}{3,0}$ & $\frac{3,0-3,5}{3,3}$ \\
\hline $\begin{array}{l}\text { ГАюкоацидиметрический показатемь } \\
(\text { ГАП) }\end{array}$ & $\frac{1,3-3,8}{2,6}$ & $\frac{1,2-3,9}{2,3}$ & $\frac{2,1-5,2}{3,7}$ \\
\hline $\begin{array}{l}\text { Показатель технической зремости } \\
\text { (ПТЗ) }\end{array}$ & $\frac{117,2-272,8}{181,5}$ & $\frac{105,8-258,8}{162,3}$ & $\frac{118,8-21}{169,3}$ \\
\hline $\begin{array}{l}\text { Массовая концентрация фенольных } \\
\text { соединений сусла после прессования } \\
\text { целых ягоА }\left(\Phi B_{\text {нсх }}\right), \text { мг/Ам }\end{array}$ & $\frac{128,3-510,9}{292,4}$ & $\frac{179,3-403,7}{257,0}$ & $\frac{391,9-58}{464,5}$ \\
\hline $\begin{array}{l}\text { Массовая концентрация фенольных } \\
\text { веществ сусла посме настаивания мезги } \\
\left(\Phi B_{\text {нм }}\right), \text { мг/Aм }^{3}\end{array}$ & $\frac{133,5-5}{299,6}$ & $\frac{159,3-40}{273,6}$ & $\frac{397,0-}{539,7}$ \\
\hline $\begin{array}{l}\text { Способность фенольных веществ сусла к } \\
\text { окислению }\left(\Phi B_{\text {ок }}=\left(\Phi B_{\text {исх }}-\Phi B_{\text {ох }}\right) / \Phi B_{\text {исх }}\right), \%\end{array}$ & $\frac{0,4-2}{7,4}$ & $\frac{0,5-18,3}{5,4}$ & $\begin{array}{l}1,2-10,6 \\
3,5\end{array}$ \\
\hline $\begin{array}{l}\text { Активность монофенолмонооксигена- } \\
\text { зы (МФМО), у.е./см }\end{array}$ & $\frac{0,019-0,125}{0,070}$ & $\frac{0,007-0,142}{0,059}$ & $\frac{0-0,094}{0,038}$ \\
\hline 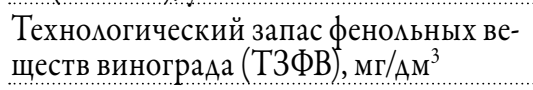 & $\frac{444-1065}{656}$ & $\frac{491,5-1007}{586}$ & $\frac{599-710}{665}$ \\
\hline $\begin{array}{l}\text { Мацерирующая способность виногра- } \\
\mathrm{Aa}\left(\Phi \mathrm{B}_{\text {ман. }}=\Phi \mathrm{B}_{\text {нм}}{ }^{*} 100 / \Phi \mathrm{B}_{\text {исх }}\right), \%\end{array}$ & $\frac{61,5-137,8}{103}$ & $\frac{69,6-132,5}{107}$ & $\frac{96,5-156,7}{117}$ \\
\hline $\begin{array}{l}\text { Способность винограда к отааче фе- } \\
\text { номьных веществ при прессовании це- } \\
\text { мых ягоА }\left(\Phi B_{\text {от }}=\Phi B_{\text {ис* }} * 00 / \text { T3 } \Phi \mathrm{B}\right), \%\end{array}$ & $\frac{25,2}{45}$ & $\frac{23,8-53,5}{38}$ & $\frac{58,5-81,8}{70}$ \\
\hline $\begin{array}{l}\text { УАемьная ферментативная активность } \\
\text { сусла }\left(\text { МФМО*100/ } \Phi B_{\text {иск }}\right) \text {, у.е./мг }\end{array}$ & $\underline{0,006-}$ & $\frac{0,002-(}{0,027}$ & $\frac{0,005-1}{0,009}$ \\
\hline
\end{tabular}


The effect of grapvine varietal features on the quality and composition of volatile substances of young brandy distillates

Группа интродуцированных сортов отмичалась от остальных более низкими среАними значениями показатемя мацерирующей способности винограАa $\left(\Phi B_{\text {мац }}\right)$ (на 4-13\%), но высокой ферментативной активностью (МФМО) (на 19-84\%) и способностью феномьных веществ сусла к окислению $\left(\Phi B_{\text {ок }}\right)$ (на $35-111 \%$ ).

Группа сортов винограда семекции Института «Магарач» характеризова$\Lambda$ ась более низкими средними значениями массовой концентрации фенольных соеАинений сусла после прессования цемых ягоА $\left(Ф \mathrm{~B}_{\text {исх }}\right)$ (на 12-45\%) и после настаивания мезги (ФВ также способности винограда к отдаче фенольных веществ при прессовании целых ягоА (ФВ от) (на 18-84\%).

Наиболее высокие средние значения образцов третьей группы отмечены по показателям технологического запаса феномьных веществ винограда (ТЗФВ) (Ао $13 \%$ ), способности винограда к отдаче фенольных веществ при прессовании цемых ягоА $\left(Ф \mathrm{~B}_{\text {от }}\right)$ (на 35$46 \%)$, мацерирующей способности винограда (на 9-14\%), массовой концентрации феномьных веществ сусла после настаивания мезги $\left(\Phi_{\text {нм }}\right)$ (на 80-97 \%), массовой концентрации фенольных соеАинений сусла после прессования цемых ягоА $\left(Ф \mathrm{~B}_{\text {исх }}\right)$ (на 59-81\%), но при наиболее низких значениях МФМО активности (на 55-84\%) и удемьной ферментативной активности сусла (на 200$211 \%)$.

Таким образом, можно отметить особенности сортов винограда с учетом их принаАлежности к одной из условных групп: интродуцированных сортов - сравнительно низкая мацерирующая способность и более высокие оксидазная активность и способность феномьных веществ сусла к окислению; селекционных сортов - низкая способность к отАаче $\Phi В$; аборигенных - высокий уровень запаса фенольных веществ и степени их отАачи при низкой способности к окислению и МФМО активности.

Изучено вмияние исследуемых показателей качества винограда на состав ароматобразующих веществ виноматериалов, что позволико выявить наибомее значимые: массовую концентрацию сахаров, титруемых кислот, феномьных соеАинений сус а $\left(\Phi \mathrm{B}_{\text {исх }}\right)$, технологический запас фенольных веществ в винограде, вемичину рН сусла и МФМОактивность $[14,15]$. Установлена их взаимосвязь с содержанием основных
Chursina O.A., Legasheva L.A., Zagorouiko V.A., Solovyova L.M.,

групп метучих компонентов виноматериа , которая описывается уравнениями регрессии вида:

$$
\mathrm{y}_{1}=1,23 \mathrm{x}_{1}+18,18 \mathrm{x}_{2}+669,59 \mathrm{x}_{3}-0,54 \mathrm{x}_{4}+0,39 \mathrm{x}_{5}-2493,24 \mathrm{x}_{6}-
$$

2041,65 (при $\mathrm{r}=0,93 ; \mathrm{R}^{2}=0,87$ );

$\mathrm{y}_{2}=0,11 \mathrm{x}_{1}-3,62 \mathrm{x}_{2}+42,13 \mathrm{x}_{3}-0,095 \mathrm{x}_{4}-0,043 \mathrm{x}_{5}-233,49 \mathrm{x}_{6}-12,90$

(при $\mathrm{r}=0,63 ; \mathrm{R}^{2}=0,40$ );

$\mathrm{y}_{3}=0,004 \mathrm{x}_{1}+0,07 \mathrm{x}_{2}-1,95 \mathrm{x}_{3}+0,004 \mathrm{x}_{4}+0,0003 \mathrm{x}_{5}-11,62 \mathrm{x}_{6}+6,60$

(при $\mathrm{r}=0,48 ; \mathrm{R}^{2}=0,23$ );

$\mathrm{y}_{4}=0,478 \mathrm{x}_{1}-12,57 \mathrm{x}_{2}-101,69 \mathrm{x}_{3}+0,42 \mathrm{x}_{4}-0,17 \mathrm{x}_{5}+913,45 \mathrm{x}_{6}+$ 392,99 (при $\left.\mathrm{r}=0,68 ; \mathrm{R}^{2}=0,46\right)$,

гАе $\mathrm{y}_{1}$ - массовая концентрация высших спиртов в виноматериале, мг/ $\mathrm{AM}^{3} ; \mathrm{y}_{2}$ - массовая концентрация среАних эфиров в виноматериале, мг/Aм ${ }^{3} ; \mathrm{y}_{3}$ - массовая концентрация ацьАегидов в

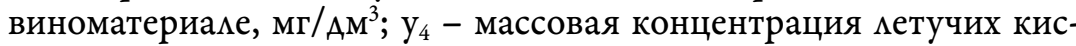
$\Lambda о т ~ в ~ в и н о м а т е р и а л е, ~ м г / \mathrm{AM}^{3} ; \mathrm{x}_{1}$ - массовая концентрация сахаров в винограде, г/AM${ }^{3} ; \mathrm{x}_{2}-$ массовая концентрация титруемых кислот

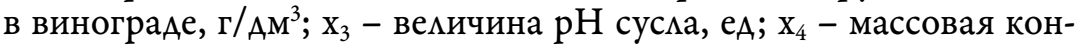
центрация фенольных веществ в сусле после прессования целых

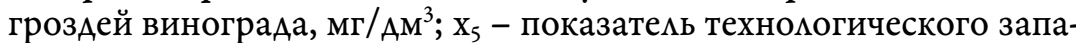
са феноцьных веществ в винограАе, мг/Aм ${ }^{3} ; \mathrm{x}_{6}-\mathrm{MФМО-активность}$ сусла, у.е.

Анамогичные регрессионные уравнения выведены также Аля коньячных Аистиццятов, выработанных из этих виноматериалов. Аля высших спиртов, в частности, эта зависимость имеет виА:

$\mathrm{y}_{1}=-0,45 \mathrm{x}_{1}-3,89 \mathrm{x}_{2}+136,44 \mathrm{x}_{3}-0,66 \mathrm{x}_{4}+0,78 \mathrm{x}_{5}-1046,50 \mathrm{x}_{6}-$ 165,0 (при $\mathrm{r}=0,679 ; \mathrm{R}^{2}=0,460$ ).

Полученные результаты свидетельствуют о тесной взаимосвязи биохимических и физико-химических показателей винограАа с составом метучих компонентов коньячных виноматериалов и полученных из них Аистиццятов.

Виноматериалы, произведенные из интродуцированных сортов винограда, отмичацись от селекционных сортов повышенным содержанием суммы метучих компонентов (на 21,1\%), из них средних эфиров (на 61,6 \%), в т.ч. этилацетата (на 55,4 \%), этилсукцината (на $67 \%$ ), компонентов энантового эфира (на 34,8 \%), а также амьдегидов (на 33,3 \%), метучих кислот (на $67 \%$ ) при незначительно сниженном содержании изоамимового спирта (на 4,6 \%) и феницэтимового спирта $(1,75 \%)$ (рис. 1$)$.

Состав метучих веществ коньячных виноматериалов из аборигенного сорта винограда Шабаш характеризовался наиболее высоким (в 2,6 раза) содержанием их суммы, в т.ч. среАних эфиров (на 70,4 \%), этимацетата (на 50,0 \%), Аиэтиксукцината (на 96,0\%), компонентов энантового эфира (на 17,4\%), а также высших спиртов (на $17,7 \%$ ), изоамимового спирта (на 23,8 \%), фенимэтимового спир-

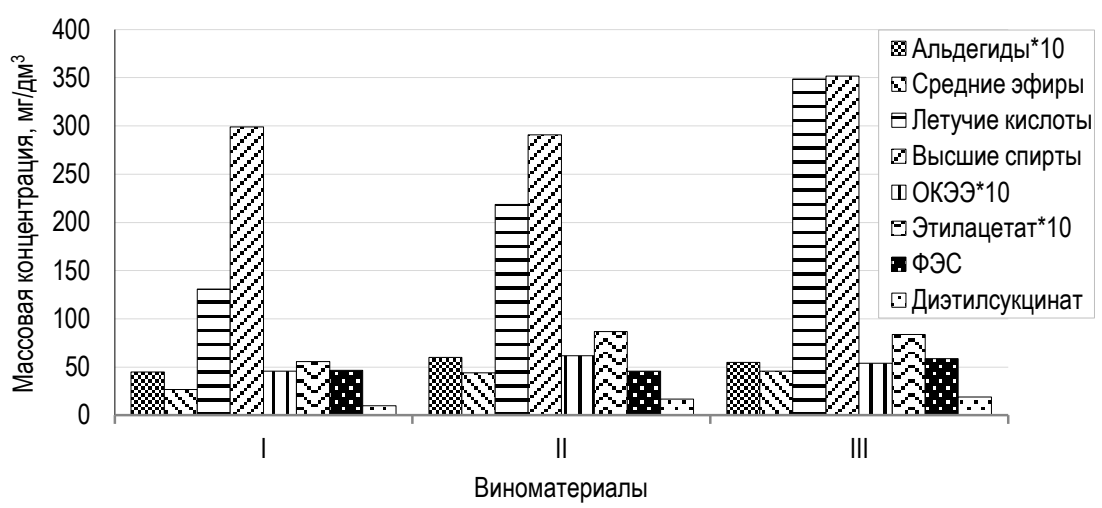

Рис. 1. Содержание летучих компонентов в коньячных виноматериалах из винограда: I - интродуцированных сортов; II - селекционных сортов; III - аборигенного сорта

Fig. 1. The volatile components content in brandy wine materials from grapes of: I - introduced cultivars; II - selection cultivars; III - aboriginal varieties 
та (на $27,9 \%$ ) и ацьдегидов (на 22,2 \%).

Важным критерием Аһя оценки качества коньячных Аистиццятов явцяется соотношение суммарного количества средних эфиров и высших спиртов (СЭ/ BC) $[1,2]$. Анализ Аанного критерия применительно к коньячным виноматериалам с учетом их принаАлежности к условной группе сортов винограда показац, что, независимо от кмиматических условий года и зоны произрастания винограда, виноматериалы, полученные из интродуцированных сортов винограда, отмичались наиболее высоким содержание эфиров и сравните ьно низким уровнем высших спиртов, соотношение ароматобразующих компонентов СЭ/ВС оказацось наиболее высоким, в среднем 0,18 (рис. 2). Несколько ниже значения установ ены в виноматериалах из аборигенного сорта Шабаш - 0,14 и минимальные в селекционных сортах - 0,10.

Высоким содержанием средних эфиров отличались образцы виноматериалов, полученные при переработке винограда с массовой концентрацией сахаров не ниже 170 г/ м $^{3}$ (Ркацители, Комомбар, Аниготе). ОАнако при перезревании винограда (массовая концентрация сахаров 220-236 г/ AM $^{3}$ ) интродуцированных сортов (Ркацители, Совиньон земеный) и аборигенного сорта (Шабаш) в виноматериалах накапмивацось также значительное количество высших спиртов. Такой же высокий их уровень, но при низком содержании среАних эфиров отмечен и в образцах, полученных из се$\Lambda$ екционных сортов винограАа при массовой концентрации сахаров 120-148 г/Ам ${ }^{3}$ (Первенец Магарача, Рислинг Магарача).

Выявценные в сортовых коньячных ви-

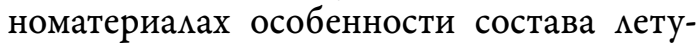
чих примесей сохраняются и в коньячных Аистиццятах, однако их соотношение нескоцько изменяется (рис. 3).

При перегонке виноматериалов в коньячных Аистиццятах значите ьно снижается содержание метучих кислот в результате отбора хвостовой фракции, при этом Аоля высших спиртов в сумме метучих примесей возрастает (Ао 79-82 \%). В результате перераспределения метучих компонентов наиболее существенное снижение Аоли эфиров отмечено в образцах из селекционных и аборигенного сортов.

Аифференцирование молодых коньячных Аистиццятов по показатецям высших спиртов и среАних эфиров в зависимости от сорта винограда сохраняет тенденцию, установценную Аля коньячных виноматериалов (рис. 4).

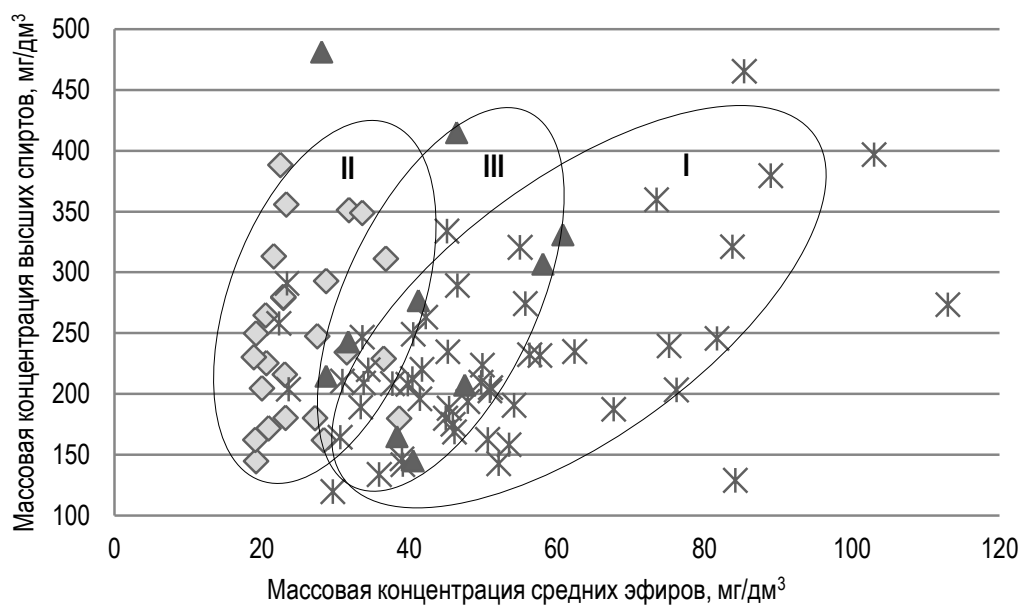

Рис. 2. Дифференцирование по показателям массовой концентрации средних эфиров и высших спиртов коньячных виноматериалов, полученных из винограда: I - интродуцированных сортов; II селекционных сортов; III - аборигенного сорта

Fig. 2. Differentiation in terms of mass concentration of medium esters and higher alcohols of brandy wine materials obtained from grapes of: I introduced cultivars; II - selection cultivars; III - aboriginal varieties

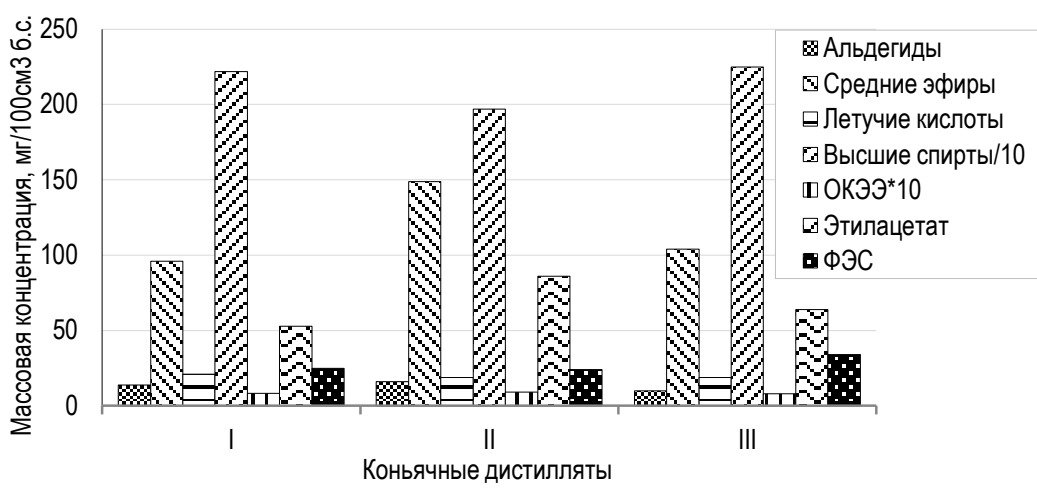

Рис. 3. Содержание летучих компонентов в коньячных дистиллятах из винограда: I - интродуцированных сортов; II - селекционных сортов; III - аборигенного сорта

Fig. 3. The content of volatile components in cognac distillates from grapes: I - introduced varieties; II - selection varieties; III - aboriginal variety

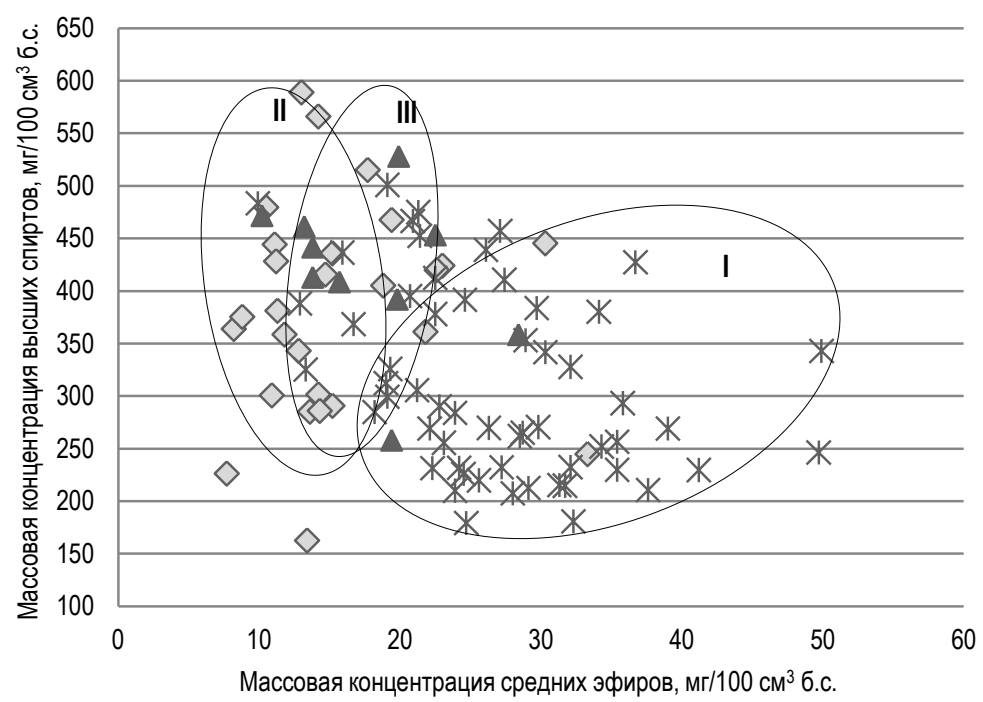

Рис. 4. Дифференцирование по показателям массовой концентрации средних эфиров и высших спиртов коньячных дистиллятов, выработанных из винограда: I - интродуцированных сортов; II селекционных сортов; III - аборигенного сорта

Fig. 4. Differentiation in terms of mass concentration of medium esters and higher alcohols of brandy distillates produced from grapes of: I introduced cultivars; II - selection cultivars; III - aboriginal varieties 
The effect of grapvine varietal features on the quality and composition of volatile substances of young brandy distillates
Chursina O.A., Legasheva L.A., Zagorouiko V.A., Solovyova L.M.,

Solovyov A.E., Udod E.L., Martynovskaya A.V., Uluantsev S.O., Gaske Z.I
WINEMAKING
Органолептическая оценка виноматериалов и молодых коньячных Аистимлятов показаца преимущество образцов, полученных из интродуцированных сортов винограда, более низкие бамлы (на 0,03$0,08)$ отмечены в образцах, выработанных из селекционных сортов винограда.

Выводы. Таким образом, выявцены основные критерии оценки качества винограда Аця коньячного производства и установлена их тесная связь с соАержанием метучих примесей в коньячных виноматериалах и Аистимлятах. Показано, что наиболее значимыми из исследуемых показателей качества винограда явцяются массовая концентрация сахаров, титруемых кислот, фенольных соединений сусла $\left(\Phi B_{\text {исх }}\right)$, технологический запас фенольных веществ в винограде, величина рН сусла и МФМО-активность. Выведены уравнения регрессии, устанавливающие зависимость содержания метучих примесей виноматериалов и молодых коньячных Аистиццятов от показателей качества винограда.

Установцено вцияние сорта винограда на качество коньячных виноматериалов и Аистиццятов. Показано, что образцы, полученные из интродуцированных сортов винограда, характеризуются наиболее высокими значениями соотношения среАних эфиров и высших спиртов, что свидетельствует о высоком их качестве. Особенностью состава коньячных виноматериалов и Аистилцятов из селекционных сортов явАяется высокая Аоля высших спиртов и сравнительно низкая - среАних эфиров. Повышению критерия способствует переработка винограда при массовой концентрации сахаров не ниже 160 г/AM².

\section{Источник финансирования}

Работа выполняется в рамках Государственного задания Минобрнауки России № 0833-2019-0012.

\section{Financing source.}

The study was conducted under public assignment № 0833-2019-0012.

\section{Конфликт интересов Не заявлен. \\ Conflict of interests No declared.}

\section{Список литературы / References}

1. Мартыненко Э.Я. Технология коньяка. - Симферополь: Таврида, 2003. - 320 c.

Martynenko Je.Ja. Tehnologija kon'jaka [Cognac technology]. Simferopol', Tavrida Publ., 2003, 320 p. (in Russian).

2. Скурихин И.М. Химия коньяка и бренди. - М.: ДеЛипринт, 2005. $-296 \mathrm{c}$.

Skurihin I.M. Himiya kon'yaka $i$ brendi [Chemistry of cognac and brandy]. Moscow, DeLiprint Publ., 2005, 296 p. (in Russian)

3. Cantagrel R., Galy B. From vine to cognac // In: Lea AGH, Piggott JR, editors. Fermented beverage production. 2nd ed. New York: Kluwer Academic. Plenum Publishers, 2003. pp. 195-212.

4. Lurton L., Ferrari G., Snakkers G. Cognac: production and aromatic characteristics // In: Pigott JH, editor. Alcoholic beverages: sensory evaluation and consumer research. Cambridge: Woodhead Publishing
Ltd. 2011. pp. 242-266. DOI: 10.1016/B978-0-85709-051-5.50011-0.

5. Managing Wine Quality: Viticulture and Wine Quality. Edited by A. Reunolds. - Cambridge: Woodhead Publishing Limited, 2010. - 620 p.

6. Milicevic B., Banovic M., Kovacecic-Ganic K., Gracin L. Impact of grape varieties on wine distillates flavor // Food technology and Biotechnology. 2002. Vol.40. pp. 227-232. URI: https:/hrcak.srce hr/178495.

7. Tsakiris A., Kallithraka S., Kourkoutas Y. Grape brandy production, composition and sensory evaluation // Jornal of the Science of Food and Agriculture. 2014. Vol. 94 (3). pp. 404-414. DOI: 10.1002/jsfa.6377.

8. Мартыненко Н.Н. Современная технология получения коньячных виноматериалов высокого качества // Виноделие и виноградарСтво. 2018. № 1. С. 15-28.

Martynenko N.N. Sovremennaya texnologiya polucheniya konyachnyx vinomaterialov vysokogo kachestva [Modern technology of quality brandy base wines production] // Vinodelie $i$ vinogradarstvo, 2018, № 1, pp. 15-28 (in Russian).

9. Оселедцева И.В., Кирпичева Л.С. Оценка степени влияния сортового фактора на варьирование параметров состава легколетучей фракции коньячных виноматериалов и молодых коньячных дистиллятов // Весник АПК Ставрополья. 2015. № 1 (17). С. 246-252.

Oseledceva I.V., Kirpicheva L.S. Ocenka stepeni vliyaniya sortovogo faktora na varirovanie parametrov sostava legkoletuchej frakcii konyachnyx vinomaterialov $i$ molodyx konyachnyx distillyatov [Impact assessment of the varietal factor on parameter variation in the volatile factions of brandy base wine and young brandy distillates] // Vesnik APK Stavropolya, 2015, № 1 (17), pp. 246-252 (in Russian).

10. Rib'ereau-Gayon P., Dubourdieu D., Doneche B., Lonvaud A. Handbook of Enology Volume 1. The Microbiology of Wine and Vinifications. 2nd Edition. Chichester, UK: John Wiley \& Sons Ltd, 2006. - 497 p.

11. Roscnfeld E., Beauvoit B., Blondin B., Sflmon J. Oxygen consumption by anaerodic Saccharomyces cerevisiae under enological conditions: effect on fermentation kinetics // Microbiology. Appl Environ Microbiol. 2003. Jan 69 (1). pp. 113-121. DOI: 10.1128/AEM.69.1.113-121.2003.

12. Saerens S.M., Delvaux F.R., Verstrepen K.J., Thevelein J.M. Production of volatile esters in Saccharomyces cerevisias // Microbial Biotechnology. 2010. Vol. 3 (2). pp. 165-177. DOI: 10.1111/j.17517915.2009.00106.x.

13. Santis D., Frangipane M.T., Brunori E., Cirigliano P., Biasi R. Biochemical markers for enological potentiality in a grapevine aromatic variety under different soil types // Am. J. Enol. Vitic. 2016. 68 (1). pp. 100-111. DOI: 10.5344 /ajev.2016.15123.

14. Чурсина О.А., Легашева Л.А., Загоруйко В.А., Яланецкий А.Я., Соловьева Л.М., Соловьев А.Е., Удод Е.Л., Мартыновская А.В., Гаске 3.И., Ульянцев С.О. Влияние сортовых особенностей винограда на качество коньячных виноматериалов // Виноградарство и виноделие: Сб. научных трудов НИВиВ «Магарач», Ялта. 2018. Т. 47. C. $71-74$.

Chursina O.A., Legasheva L.A., Zagorujko V.A., Yalanetskii A.Ya., Solovyova L.M., Soloviev A.E., Udod E.L., Martynovskaya A.V., Gaske Z.I., Uluantsev S.O. Vlijanie sortovyb osobennostej vinograda na kachestvo kon'jachnyh vinomaterialov [The impact of varietal peculiarities on the quality of brandy wine materials].//Vinogradarstvo i vinodelie: Sb. nauchnyb trudov NIViV «Magarach», Yalta, 2018, Vol. 47, pp. $71-74$ (in Russian).

15. Чурсина О.А., Загоруйко В.А., Легашева Л.А., Мартыновская А.В. Биохимическая оценка винограда для коньячного производства // Проблемы развития АПК региона. 2018. № 1 (33). С. 154-163.

Chursina O.A., Zagorujko V.A., Legasheva L.A., Martynovskaja A.V. Biobimicheskaja ocenka vinograda dlja kon'jachnogo proizvodstva [Biochemical assessment of grapes for brandy production] // Problemy razvitija APK regiona, 2018, № 1 (33), pp. 154-163 (in Russian).

16. Агеева Н.М., Аванесьянц Р.В. Биохимические особенности про- 
изводства коньячных виноматериалов. Краснодар, 2011. - 135 с.

Ageeva N.M., Avanes'janc R.V. Biohimicheskie osobennosti proizvodstva kon'jachnyb vinomaterialov [Biochemical peculiarities of brandy base wine production]. Krasnodar, 2011, 135 p. (in Russian).

17. Гугучкина Т.И., Якименко Е.Н., Прах А.В., Трошин Л.П. Биохимический состав виноматериалов из интродуцированных сортов винограда, выращенных в условиях Темрюкского района Краснодарского края // Научный журнал КубГАУ. 2014. №101(07). C. $136-150$.

Guguchkina T.I., Jakimenko E.N., Prah A.V., Troshin L.P. Biobimicheskij sostav vinomaterialov iz introducirovanny sortov vinograda, vyrashbennyb v uslovijab Temrjukskogo rajona Krasnodarskogo kraja [Biochemical composition of wine materials from introduced grapevine cultivars grown in the Temriuk region of the Krasnodar krai]. Nauchnyj zhurnal KubGAU, 2014, № 101 (07), pp. 136-150 (in Russian).

18. Ильина И.А., Ненько Н.И., Петров В.С., Сундырева М.А., Запорожец Н.М., Схаляхо Т.В. Физиолого-биохимические исследования морозоустойчивости межвидовых гибридов винограда в осенне-зимний период // Плодоводство и виноградарство Юга России. 2013. № 23(5). С. 19-32. URL: http://journalkubansad.ru/ pdf/13/05/03.pdf.

Il'ina I.A., Nen'ko N.I., Petrov V.S., Sundiryeva M.A., Zaporozhez N.M., Shalyaho T.V. Fiziologo-biohimicheskie issledovanija morozoustojchivosti mezhvidovyh gibridov vinograda $v$ osennezimnij period [Physiological and biochemical studies on frostresistance of interspecific hybrids of grapevines in the autumn-winter period]. Plodovodstvo i vinogradarstvo Juga Rossii, 2013, № 23 (5), pp. 19-32 (in Russian).

19. Левченко С.В. Бойко В.А., Белаш Д.Ю. Влияние регуляторов роста на морозоустойчивость винограда // Русский виноград. 2017. T. 6. C. 156-163.

Levchenko S.V., Bojko V.A., Belash D.Ju. Vlijanie reguljatorov rosta na morozoustojchivost' vinograda [The impact of growth regulators on vine frost resistance]. Russkij vinograd, 2017, V. 6, pp. 156-163 (in Russian)

20. Rodriguez-Muciz G., Miranda M.A., Marin M.L. A time-resolved study on the reactivity of alcoholic drinks with the hydroxyl radical // Molecules. 2019. Vol. 24 (2). 9 p. DOI: 10.3390/molecules24020234.

21. Погосян К.С. Физиологические особенности морозоустойчи- вости виноградного растения. - Ереван: Изд-во АН Армянской CCP, 1975. - 237 c.

Pogosjan K.S. Fiziologicheskie osobennosti morozoustojchivosti vinogradnogo rastenija [Physiological peculiarities of frost resistance of a vine plant]. Erevan, AN Armjanskoj SSR Publ., 1975, 237 p. (in Russian).

22. Litchev V. Influence of oxidation processes on the development of the taste and flavor of wine distillates // Am. J. Enol. Vit. 1989. Vol. 40. pp. 31-35.

23. Aleixandre-Tudo J.L., Weightman C., Panzeri V., Nieuwoudt H.H., du Toit W.J. Effect of skin contact before and during alcoholic fermentation on the chemical and sensory profile of South African Chenin blanc white wines / S. Afr. J. Enol. Vitic. 2015. Vol. 36 (3). pp. 366-376. URI: http://hdl.handle.net/10019.1/100782.

24. Общие технологические инструкции приготовления коньяков // Сборник основных правил, технологических инструкций и нормативных материалов по производству винодельческой продукции / под ред. Н.Г. Саришвили. - М.: Пищепромиздат, 1998. - C. 186-187.

Sarishvili N.G. Obshbie tebnologicheskie instrukcii prigotovlenija kon'jakov. Sbornik osnounyh pravil, tehnologicheskih instrukcij $i$ normativny mate-rialov po proizvodstuu vinodel'cheskoj produkcii [General technological instructions for brandy production. Collection of basic rules, technological instructions and regulatory materials for the production of wine products]. Moscow, Pishhepromizdat Publ., 1998, pp. 186-187 (in Russian).

25. Методические указания. Методика оценки сортов винограда по физико-химическим и биохимическим показателям / РД 0033483.042-2005. - Ялта: ИВиВ «Магарач», 2005. - 22 с.

RD 0033483.042-2005. Metodicheskie ukazanija. Metodika ocenki sortov vinograda po fiziko-bimicheskim i biobimicheskim pokazateljam [Recommended practices. Methodology for evaluating varieties of vines based on their physico-chemical and biochemical indicators]. Yalta, IViV «Magarach» Publ., 2005, 22 p. (in Russian).

26. Методы технохимического контроля в виноделии / под ред. В.Г. Гержиковой. - Симферополь: Таврида, 2009. - 303 с.

Gerzhikova V.G. Metody tehnobimicheskogo kontrolja v vinodelii [Technological Control Methods in Wine-making]. Simferopol', Tavrida Publ., 2009, 303 p. (in Russian). 